\title{
Research on Intergenerational Inheritance of Family Business Based on Relational Contract
}

\author{
Li-ping Lou ${ }^{1}$, Zhi-min Deng ${ }^{2}$ \\ ${ }^{1)}$ College of International Business, Zhejiang Yuexiu University of Foreign Languages, Shaoxing, Zhejiang, China \\ (louisme@sina.com) \\ 2) School of Economics and Trade Management, Taizhou University, Jiaojiang, Zhejiang, China (tzxydzm@163.com)
}

\begin{abstract}
The problem of intergenerational inheritance of family business has a great influence on not only the family business itself, but also the stability of China's social and economic life. From the perspective of the relational contract, the paper analyses the positive role of the reputation, trust and social networks in the intergenerational inheritance of family business. The paper also proposes the optimization of family business governance model and the building of stable institutional framework of family business on the basis of rational utilization of enterprise internal relational contract, to promote the development of family business towards standardization.
\end{abstract}

Keywords - Relational Contract, Family Business, Intergenerational Inheritance, Social Capital

\section{基于关系型契约的家族企业代际传承研究}

\author{
${\text { 楼莉萍 }{ }^{1} \text { 邓志敏 }}^{2}$ \\ 1) 浙江越秀外国语学院国际商学院, 绍兴, 浙江, 中国 \\ 2) 台州学院经贸管理学院, 椒江, 浙江, 中国
}

摘 要 家族企业的代际传承问题不仅对家族企业本身影响重大, 对中国社会经济生活的稳定也会产生较大影响。文章从关系型 契约入手, 分析了声誉、信任、社会关系网络等在家族企业代际传承中的积极作用, 提出在合理利用企业内部关系型契约的基础上, 优化家族企业治理模式，构建家族企业稳定的制度框架，促进家族企业走向规范化发展。

关键词 关系型契约，家族企业，代际传承，社会资本

\section{1. 引言}

中国是一个深受家族文化传统影响的国度，家族可 以说是影响中国人社会生活、经济生活、文化生活的核 心因素。在世界各国, 家族企业都大量的生存和发展着, 并且占据着企业规模总量的半壁江山。中国新兴的家族 企业是伴随着改革开放的大潮兴起的，经过三十几年的 风雨搏击, 家族企业掌权人的交接班问题迫在眉睫。企 业家希望“家业常青”，代际传承却陷入“富不过三代”。 据 Astrachan(2000)统计, 即使在美国, 整体商业环境相 对比较稳定, 私有财产保护政策比较到位, 也只有 $30 \%$ 的家族企业能成功地过继给第二代; $12 \%$ 的家族企业能 成功地

浙江省社会科学界联合会研究课题成果（项目编号 2013B046）
过继给第三代; $3 \%$ 的家族企业能成功地过继给第四代。 即便如此, 在中国现有环境下, 子承父业的代际传承模 式依然是家族企业的合理选择。

家族企业的经营成功主要源自于创业家族对企业的 巨大贡献, 因而家族企业在企业所有权、控制权、经营 管理权和继任者选拔等治理行为上与一般公司有显著差 别。家族企业的治理模式目前主要有关系治理和契约治 理两种形式。不同家族企业由于在企业规模、经营理念、 发展阶段和外部环境的差异, 其所偏好的治理模式有所 不同。但家族企业基本共同的治理目标主要有两个: 一 是通过选择合适的企业治理模式减少代理成本, 降低交 易风险, 实现家族企业价值的增值; 二是通过家族财富 的代际传承实现基业常青。 


\section{2. 关系型契约与家族企业传承}

在中国这样一个高度重视关系的社会中, 家族企业 的创业者往往会根据自己对企业员工的信任程度和彼此 的接触程度, 将员工分为自己人、中间人和外人。在此 基础上, 华人家族企业的内部契约有三种类型: 市场契 约、关系契约、责任契约 ${ }^{[1]}$ 。关系型契约的思想最早源 于美国法学家 Macneil (1978)所提出的关系型契约理论 (relational contract theory)。Macneil 把契约分成: 个别性 契约 (discrete contract) 和关系型契（relational contract） 两种形态。其中关系型契约 “是当事人之间规划将来交换 过程的各种关系, 必然具有关于未来合意的性 质”Macneil 认为, 契约的关系性主要表现在以下几个方 面: 交换物一般难以测量, 交换中嵌入了私人关系, 契约 将在长时间内持续且难以被转让, 事先一般难以对交易 进行精确的计划, 由契约双方共担成本、共享收益, 契 约双方认识到在履约过程中会存在很多困难, 参与者需 要通过彼此的协调来加以解决, 契约中的内生性义务不 需要明文规定等。当交换关系中出现较强的关系性时, 关系型契约就会形成 ${ }^{[2]}$ 。

家族企业的经营过程中存在着大量的关系型契约。 家族企业以血缘、亲缘、地缘等稳定的社会关系网络为 依存, 其中相对稳定的关系群体有利于信息的高速准确 传递, 基于声誉机制的关系型契约可发挥的空间很大, 关系型治理在这些群体中非常重要且必不可少。家族企 业的代际传承不仅是企业资产所有权和控制权的转移, 更重要的是能否实现企业家的社会文化资本的传递 ${ }^{[3]}$ 。 但关系型契约本身非正式、自我实施的特点, 对家族企 业的创业者和继任者而言, 很难进行有效的转移或传递, 因此如何尽可能实现关系型契约的有效传承, 对家族企 业来说是一个较大的挑战。

\section{3. 关系型契约的作用机理}

Macneil 认为, 关系型契约是一种默认契约、长期 契约, 它主要依靠交易双方彼此之间的长期交往、沟通 交流来达成共识, 并在实施过程中不断完善、充实, 确 保实现契约各方的互惠互利。关系型契约的表现形式是 非常多样化的, 家族企业老板与下属之间的默契信任是 典型的关系契约。很多家族企业在其高层管理人员的劳 动合同中并未明确其工作任务分配、晋升、奖惩、终止 雇佣条件等, 但这并不影响企业经营的正常运行; 家族 企业的供应链也很有特色, 很多企业与供应商在长期合 作中形成了高度的默契, 交易双方之间甚至没有正式的 采购合同, 双方出现纠纷时也主要靠互相沟通来解决, 通常不会诉诸法律。任何契约的实施都需要一定的机制
保障, 关系型契约是依靠契约双方的自我履约机制来实 现的。

在关系型契约的自我履约机制中，信任是一个重要 的影响变量。家族企业的经营过程中存在着大量的信任 基因, 企业内部的管理团队通常对创业者具有强烈的信 任, 创业者往往以其独特的管理艺术、人格魅力, 形成 与雇员之间的高度信任与良好互动, 这是家族企业关系 型契约的特色所在。而在企业外部, 家族企业的创业者 通过多年累积的社会资本及其与外部利益相关者长期合 作所积聚的声誉、社会关系、政治关系等专有性资产, 借助信任确保关系型契约的执行效力得以有效保障 ${ }^{[4]}$ 。 企业声誉也可看作是关系型契约的另一个重要影响变 量。声誉是企业的一种无形资产，企业的良好声誉可以 为其创造融洽的合作气氛, 降低企业的交易成本, 对内 对外都可为企业的长期稳定经营提供一种保障。在关系 型契约的自我履约过程中, 经常借助于某种私人惩罚的 形式来惩戒不诚信的经营行为。如果企业有不诚信行为, 其市场声誉被破坏, 他人对该企业的信任度就会降低, 必然增加其在日后经营中的交易成本。

\section{4. 关系型契约对家族企业代际传承的积极作用}

中国的多数家族企业产生并发展于农村, 在发展早 期创业者们面对纷繁复杂的市场环境、政商关系，不得 不依赖于基于血缘、地缘而形成的人际关系，不自觉地 依靠当地政府, 并与他们达成广泛的关系型契约。大家 普遍接受的观点是, 家族企业创业者的声誉、社会关系 和政治关系、企业家精神等专用性资产是很难复制或转 移给继任者的。如果创业者所拥有的社会资本、企业家 精神等作为关系型契约中的重要内容不能传承给继任 者, 家族企业的代际传承就是失败的。

\section{1 强化内部关系型契约, 优化家族企业治理模式}

家族企业以血缘、亲缘、地缘为纽带, 是家族与企 业的统一, 企业内部存在着复杂的利益关系, 家族成员 之间存在着以(血)亲族身份为纽带的人格化关系契约。 家族企业与其他企业的本质特征差别就在于, 它是一种 “嵌入”于家庭组织结构及其治理机制之上的关系契约。 这类契约的缔结、执行、维护和变化均以家族内部人格 化关系契约为基础, 家族成员之间的关系融洽与否会给 企业内部关系契约带来不同的执行结果。

在中国目前法制环境不够完善, 职业经理人制度不 够健全的情况下, 家族企业代际传承的长处在于, 家族 内部产生的继任者受到忠诚和伦理关系的约束, 会自觉 克制自己的不良行为和隐藏信息的动机, 减少继任者发 
生道德风险的可能性。如果家族的某个成员选择背叛企 业内部的关系型契约, 他就会失去其在家族生活博亦中 所长期积累的物质财产 (的分享权) 以及利用家族人际网 络融通家族资本的可能性, 这些构成了家族人力要素背 叛企业(家族)利益目标的强大“退出成本”。 ${ }^{[5]}$ 正因如此, 家族企业内部关系型契约的执行和维护具有很强的自我 实施、自我维系特征。信任和忠诚密切相关, 忠诚是在 对企业价值和目标利益高度认同基础上的服从和效忠, 经过良好培养的继任者会表现出某些利他主义的行为特 征, 主动承担更多风险而不计个人得失, 具有高度的敬 业奉献精神和自我牺牲精神。基于家族企业内部关系型 契约的家族治理模式, 不仅可以降低交易成本, 而且有 利于加强企业内部控制, 保证企业决策在执行过程和执 行效果反馈的迅速性。

\section{2 破解家长式权威, 构建家族企业稳定的制度框架}

目前大多数的中国家族企业是在改革开放中成长 起来的, 成功的家族企业创业者通常都具有卓绝的领导 能力、准确的判断能力和敏锐的市场开拓意识、超强的 风险承受能力, 他们在长期的企业经营管理中用企业家 的魄力、能力建立起强大的家长式权威。在企业创业和 快速成长阶段, 凭借这种家长式权威可以在企业内部迅 速决策, 快速执行, 准确抓住市场机遇, 获得明显的市 场竞争优势。但家长式权威往往意味着过分集权, 将创 业者的个人意志凌驾于企业制度和组织架构之上, 这就 会对继任者的事业传承产生很大负面性。

为保证家族企业的代际传承顺利进行, 创业者应有 意识地提前破解自己的家长式权威, 在企业内部建立比 较正式的规章制度, 构建相对稳定的组织结构, 促进家 族企业真正按照现代企业制度来运作。在此基础上, 创 业者同时应有计划地开展继任者培养计划, 为继任者创 造各种条件, 在实践中培养其经营管理能力和权威。有 条件的企业应该让继任者独挡一面, 培养其对市场的把 控能力和竞争意识。

\section{3 合理利用社会资本, 促进家族企业走向规范化发展}

家族企业的成功传承意味着企业至少有一个或几个 给企业带来竞争优势的独特核心要素在代际间的顺利留 存或转移 ${ }^{[6]}$, 其中社会资本属于家族企业典型的异质性 资源, 是家族治理模式的优势来源。在家族企业中, 创 业者的社会关系网络、信任、声誉、共同愿景等都是社 会资本的主要内容。丰富的社会资本意味着企业更容易 获得经营所需的各种资源以及其他方面的支持, 但是社 会资本是创业者在长期的经营过程中逐步建立起来的,
带有浓郁的人格化特征, 一般很难在个体、组织之间转 移或传递。因此家族企业代际传承的成败很大程度上取 决于企业社会资本在代际间的传承效果。

社会资本可分为组织社会资本和个人社会资本两类, 其 中组织社会资本包括企业内部的社会资本和家族内部的 社会资本; 个人社会资本主要指家族企业创业者个人的 社会资本。组织社会资本与企业本身高度融合, 属于企 业自身资源, 是可以顺利传承和发展的。 ${ }^{[7]}$ 个人社会资 本与创业者本人相关, 像企业主的个人声誉、人脉、政 商关系等在代际传承中会部分或完全失效, 不仅会对企 业造成较大损失, 甚至可能导致代际传承的失败。要维 持家族企业的持续发展, 确保代际传承的顺利进行, 企 业的继任者培养计划是关键一环。创业者需在继任者培 养阶段开始, 通过各种有意识的行为, 使得继任者有机 会从各个方面接触、并融入到创业者创立的各种关系网 络中, 给继任者充分展示的时间和空间, 有计划、有目 的地推动企业管理层和外界对继任者的认同感, 树立继 任者的信心和动力。同时, 企业应尽量强化组织社会资 本的建设, 弱化个人社会资本的功效。比如家族企业向 外推广企业时, 尽量以企业名义参加, 创业者以企业身 份参与各项活动, 减少对企业主的个人崇拜宣传; 企业 也要强化正式关系网络的建设, 弱化非正式关系网络的 作用。家族企业的百年基业终归需要走上规范的市场运 作，尊重市场竞争规律，依靠正常的商业往来与合作、 健康的政商关系是家族企业持续发展的必然趋势。

\section{参考文献(References)}

[1] HU Jun, ZHU Wen-sheng, PANG Dao-man, Labor Contract, Transact Cost and Relation Governance: Analysis on Internal Governance Behaviors in Chinese Clan Corporations, Journal of Jinan University, 2002, (5):14-19.

[2] Macneil I. R. The New Social Contract. Beijing: China University of Political Science and Law Press, 2004.

[3] Chu xiao-ping, Growth of Family Firms and Merge of Social Capitals. Beijing: Economic Science Press. 2004.

[4] Zhang Chuan, Yang Yu-long, Gao Miao-miao, The First Executives' Leaving, the Choice of the Successor and the Changes in Accounting Quality, Journal of Finance and Economics, 2013, (1):134-144

[5] Pollak, R.A. (1985), Atransaetions Cost Approach to Families and HousehoIds, Journal of Economic Literature, 1985, VOl. 581-608.

[6] Dou Jun-sheng, Jia Sheng-hua, How does Family Business 
Maintain Prosperous? Identification of the Elements of Intergenerational Inheritance of Family Business at the Individual Level of Entrepreneurs, Management World, 2008, (9): 105-117.
[7] Yang Yu-xiu, The Influence of Social Capital on the Intergenerational Succession of Chinese Family Business, 2011, (5): 131-137 